TITLE:

\title{
Changes in reproductive life-history strategies in response to nest density in a shell-brooding cichlid, Telmatochromis vittatus.
}

\section{$\operatorname{AUTHOR}(S)$ :}

Ota, Kazutaka; Hori, Michio; Kohda, Masanori

\section{CITATION:}

Ota, Kazutaka ... [et al]. Changes in reproductive life-history strategies in response to nest density in a shell-brooding cichlid, Telmatochromis vittatus.. Die Naturwissenschaften 2012, 99(1): 23-31

\section{ISSUE DATE:}

2012-01

URL:

http://hdl.handle.net/2433/154570

\section{RIGHT:}

The final publication is available at www.springerlink.com; この論文は 出版社版でありません。引用の際には出版社版をご確認ご利用くださ $\iota_{\circ}$; This is not the published version. Please cite only the published version. 
Changes in reproductive life-history strategies in response to nest density in a shell-brooding cichlid, Telmatochromis vittatus

Kazutaka Ota $^{* *}$, Michio Hori ${ }^{*}$, Masanori Kohda ${ }^{\dagger}$

* Department of Sciences, Faculty of Biology, Kyoto University,

Kita-Shirakawa-Oiwake, Kyoto, 606-8502, Japan. ${ }^{\dagger}$ Department of Biology and

Geosciences, Osaka City University, Sumiyoshi, Osaka 558-8585, Japan.

$\$$ Author to whom correspondence should be addressed.

e-mail: kztk@terra.zool.kyoto-u.ac.jp

Received: 16 May 2011 / Revised: 31 October 2011 / Accepted: 3 November 2011 


\begin{abstract}
To determine whether the appearance of a reproductively parasitic tactic varies, and how this variation affects territorial males of the Lake Tanganyika cichlid fish

Telmatochromis vittatus, we examined the reproductive ecology of territorial males in Mtondwe and compared it with that of a neighboring Wonzye population, where nest density differs from that at Mtondwe. In Wonzye, with high nest density, male tactics change with their body size from a territorial to a non-territorial parasitic tactic called piracy in which they conquer several nests defended by territorial males and take over the nests while females are spawning. These "pirate" males could decrease the costs incurred by travelling among nests by exclusively targeting aggregations of nests in close proximity while avoiding separate nests. Territorial males in Wonzye sacrifice the potential higher attractiveness offered by large nests and instead compete for nests farther from neighbors on which pirates less frequently intrude. In contrast, the Mtondwe population had lower nest density and piracy was absent. Given that the success of piracy depends on the close proximity of nests, nest density is likely responsible for the observed variation in the occurrence of piracy between the two populations. Furthermore, in Mtondwe, territorial males competed for larger nests and were smaller than the territorial males in Wonzye. Thus, this lower nest density may free territorial males from the selection pressures for increased size caused by both defense against nest piracy and the need to develop into pirates as they grow.
\end{abstract}

Keywords: alternative reproductive tactics; interpopulation comparison; nest choice; nest piracy; sperm competition; body size 


\section{INTRODUCTION}

Alternative reproductive tactics (ARTs) are widespread in animals, particularly in male fish (Taborsky 1994, 2001; Oliveira et al. 2008). Although tactics are genetically fixed for life in some species (Shuster and Wade 1991; Lank et al. 1995;

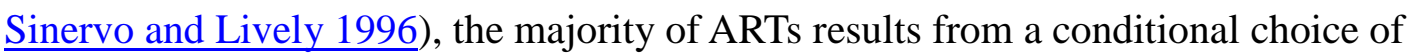
reproductive behaviors (Oliveira et al. 2008). In such cases, males are theoretically expected to adopt the tactic that generates the greatest fitness gain for their current status, which is typically related to body size (i.e., status-dependent selection model; Gross 1996; McNamara and Houston 1996). Indeed, in many species with conditional ARTs, large, dominant males are territorial and monopolize access to females, while small, subordinate males are non-territorial and steal fertilization from territorial males (Taborsky 1994, 2001; Gross 1996; Oliveira et al. 2008). Males may flexibly alter reproductive behaviors in response to changes in demographic and environmental factors (e.g., population density and predation; Endler 1995; Taborsky 2001; Kokko and Rankin 2006), suggesting that decisions as to which tactic to employ are also made condition-dependently. Consequently, the appearance and frequency of ARTs can vary among heterogeneous environments (Warner and Hoffman 1980; Balshine et al. 2001; Gamble et al. 2003; Mills and Reynolds 2003; Lukasik et al. 2006; Reichard et al. 2004; Tomkins and Brown 2004; Larison 2007; Corl et al. 2010a; Tomkins et al. 2011, but see Singer et al. 2006). Such intraspecific variation in ARTs provides a key opportunity for understanding the evolution of ARTs.

In this study, whether ARTs vary and how territorial males respond to the variation in ARTs are investigated in the Lake Tanganyika cichlid fish Telmatochromis vittatus. In the Wonzye population, at the southern end of the lake $\left(8^{\circ} 43^{\prime} \mathrm{S}, 31^{\circ} 08^{\prime} \mathrm{E}\right)$, this fish is characterized by the use of the nests built by another cichlid species, Lamprologus callipterus, and reproductive parasitism (Ota and Kohda 2006a). A "nest' consists of many empty gastropod shells which are accumulated by the nesting male $L$. callipterus (Sato and Gashagaza 1997). Females of both species deposit their entire clutches on the inner wall of shells, which they then occupy for approximately 2 weeks while caring for their brood alone. Male L. callipterus do not prevent female T. vittatus 
from breeding in parts of shells that are not used by female L. callipterus, which enables these species to cohabit the nests (Sato and Gashagaza 1997).

A territorial male $T$. vittatus defends a nest against conspecific males and attempts to monopolize mating with multiple females there. Two types of males occasionally reproductively parasitize territorial males: sneakers and pirates, which are smaller and larger than territorial males, respectively (Ota and Kohda 2006a). Sneakers dart to the shell in which females are spawning and quickly ejaculate over the entrance. Only $2.5 \%$ of sneaking attempts are successful (Ota and Kohda 2006b). Pirate males have a home range of approximately three to seven nests that are defended by territorial males (average of five) to cover. As they repeatedly travel among the nests, they take over the ongoing spawning events of territorial males by force, such that they monopolize the spawning females until spawning is over. Pirate males exclusively target aggregations of nests in close proximity while avoiding isolated nests. This enables them to conquer a greater number of nests and to save on the costs incurred by travelling among the nests (Ota and Kohda 2006b, 2011). Once having been usurped, territorial males miss the opportunity for pair spawning within the spawning event, making nest piracy a parasitic tactic that has high costs for territorial males.

The piracy tactic plays an important role in shaping the reproductive strategies of territorial males. For example, nest choice strategies are sensitive to piracy. Although nests containing more shells (i.e., larger nests) can hold more females and thus offer the higher mating success, territorial males prefer to and compete for nests that are farther away from neighboring nests so that they avoid pirates (Ota and Kohda 2006a, 2011). Territorial males cannot maximize both nest size and distance from neighboring nests in Wonzye where these parameters are independent. As a result of nest competition, larger territorial males succeed in occupying the more isolated nests, while smaller ones are forced to occupy the less isolated nests that have a greater risk of piracy. The body size of territorial males will also be influenced by piracy. Male T. vittatus adopt either territorial or piracy tactics in a size-dependent manner, in which territorial males start to employ the piracy tactic as they grow larger (Ota et al. 2010a). Because pirates are expected to have higher success than are territorial males, males will benefit from 
growing larger to employ the piracy tactic. Further, nest piracy can pose sperm competition to territorial males and thus influence their testes investment. Territorial males employ sneaking tactics after their spawning events are taken over by pirates (Ota et al. 2010a). As smaller, less competitive territorial males are more likely to fail in occupying isolated nests with lower piracy risk (Ota and Kohda 2011), they have higher probabilities of employing sneaking and thus facing sperm competition, than do larger, competitive males. In this situation, theory (Parker 1990) predicts that smaller territorial males invest in testes more than large males.

Density of L. callipterus nests is highly variable among populations, and nest density at Wonzye is higher than other populations (Ota et al. 2010b). In the Mtondwe population $\left(8^{\circ} 42^{\prime} \mathrm{S}, 31^{\circ} 07^{\prime} \mathrm{E}\right)$, which is adjacent to Wonzye, shells are much less available and nest density seems to be considerably lower. As the efficiency of the piracy tactic is influenced by nest distribution, we expect piracy to be reduced and a relaxation of the selection pressures induced by pirates on reproductive strategies of territorial males at Mtondwe. We conducted field studies in Mtondwe, to examine whether the frequency of the piracy tactic varies between the two populations and how the variation influences the abovementioned three reproductive phenotypes of territorial males, which are vulnerable to nest piracy.

\section{MATERIALS AND METHODS}

Field surveys at Mtondwe Island

The field study was conducted on the north-west coast of Mtondwe Island near Mpulungu, Zambia, in October to November 2010 when T. vittatus is reproductively active. This island is only $1 \mathrm{~km}$ away from Wonzye, and the bottom is covered with rocks between the study site and Wonzye. This suggests that the two populations of $T$. vittatus are not as genetically isolated, as has been reported for adjacent populations of many other rock-dwelling Lamprologini cichlids (Takahashi 2004; Koblmüller et al. 2007; Nevado et al. 2009; Takahashi et al. 2009, but see Duftner et al. 2006). Rock coverage, water temperature, water currents, and the availability of foods (algae, which 
prosper on the rock surfaces in the shallow areas) were considered to be similar for both populations. Prior to the observation period, we performed a census and found more than 20 nests from a wide range of the population at 6 to $9.7 \mathrm{~m}$ depth. A study area $\left(2,625 \mathrm{~m}^{2}\right)$ was established at a depth of 6.0-8.4 $\mathrm{m}$ in which 12 nests were included. Nests at Mtondwe could be easily identified as clumps of shells (Ota et al. 2010b). In this population, shells were less available and almost exclusively found at nests $(0.13$ shells $/ \mathrm{m}^{2}$ outside nests at Mtondwe, $17.83 \mathrm{shells} / \mathrm{m}^{2}$ outside nests at Wonzye; Ota, unpublished data). Other nests were at least $50 \mathrm{~m}$ away from the study area. We followed the sampling methods used at Wonzye (Ota and Kohda 2011). Prior to the observations, we caught all large males $(>40 \mathrm{~mm}$ in standard length [SL], by visual inspection, $n=25$ ) found in and around the nests. Their SLs were measured to the nearest $0.5 \mathrm{~mm}$, and the captured fish were tagged with a subcutaneous injection of a visible implant elastomer (Northwest Marine Technology, Inc., Shaw Island, WA, USA) using individual-specific colors and positions. They were then released at their original capture points. To reduce stress and injuries, all handling was conducted carefully and within a few minutes in a small transparent polyethylene bag $(140 \times 100 \mathrm{~mm})$ underwater. Each nest was then observed for 30 min four to five times (mean observation time $\pm \mathrm{SD}=133 \pm 23 \mathrm{~min}, n=12$ ) at 3 - to 4 -day intervals during which the social (aggressive and submissive) behaviors of the tagged males and the time they spent in the nests were recorded. This observation time is the same as the average time in the studies conducted at Wonzye (130 min; Ota and Kohda 2011). Territorial males were identified as those which defended nests against conspecifics. No replacement of territorial males was found during the study periods. Three nest quality traits were measured or calculated: the number of intact shells in each nest (referred as "nest size"), which was visually counted at the first observation; the distance to the nearest nest (referred to as the "nearest-neighbor distance" or NND), which was directly measured within $0.1 \mathrm{~m}$ underwater after the observations; and the frequency of nest intrusion by pirate males, which was calculated as the total number of intrusions per total observation time (referred as "piracy risk"). Pirate males were identified as those that entered several nests and dominated territorial males (Ota and Kohda 2006a, 2011). In order to determine whether there were nest quality traits that territorial males competed 
for, we examined the linear relationships between nest quality traits and SLs. This analysis was conducted because larger males are competitively superior and consequently occupy better nests (Ota 2007; Ota and Kohda 2011). The mating success of territorial males (i.e., the number of brood-caring females per nest) was not examined at this study site to avoid destroying the nests, which would be necessary to determine whether a shell was occupied. Instead, mating success was measured at 11 nests at least $50 \mathrm{~m}$ away from the study site. The nest density appeared to be similarly low in these sites. The presence of $T$. vittatus brood-caring females was visually checked by examining the shell entrance, and we counted the numbers of shells and brooders. Breeding females of another cichlid species, Neolamprologus brevis, were found in nests at both Mtondwe and Wonzye (Sato and Gashagaza 1997; Ota and Kohda 2006a). Breeding females of either species were found in 86 of the 290 shells that were visually examined. We finally crushed all shells to confirm the presence of brood-caring females. In total, 204 shells were crushed and 13 brood-caring female T. vittatus were identified. Piracy risk and NND were not measured in these nests. The linear relationship was examined between nest size and mating success using these data.

In order to examine the nest traits preferred by territorial males, the territorial males were carefully removed from all observed nests $(n=12)$ in the study area immediately after the observations, and we then checked whether new males had occupied the vacant nests 3 days after the removal (Ota and Kohda 2011). The nests occupied within 3 days were regarded as preferred nests and thus subject to competition. To determine preferred traits, nest traits were compared between nests that were immediately occupied and those not yet occupied after 3 days. Captured males were brought back to the laboratory, anesthetized with eugenol, and dissected; body mass and testes mass were determined to the nearest $0.001 \mathrm{~g}$ to examine testes investment.

To determine the effect of the operational sex ratio (OSR; the ratio of males and females that are ready to mate; Kvarnemo and Ahnesjö 1996) at nests on the decision to employ piracy tactics, all individuals found in and around the observed nests ( $<1 \mathrm{~m}$ from the center of each nest, $\mathrm{n}=12$ nests) were netted immediately after checking for reoccupation of vacant nests in the removal experiment. These fish were brought 
back to the laboratory, dissected after anesthetizing with eugenol, and sexed. Their sexual maturity was determined by assessing gonad development. Removing these fish had no effect on the number of $T$. vittatus near the nests because the number of fish surrounding the nests, as determined by visually counting them, did not differ before and after the fish were removed (Ota, unpublished data). In total, 175 T. vittatus were dissected. OSR was calculated per nest (referred to as "local" OSR) as the percentage of mature males with developed testes (testes mass $\geq 0.002 \mathrm{~g}$; Ota and Kohda 2006a) and ready-to-mate females who were defined as those with ripe eggs in their ovaries (gonad mass $\times 100 /$ body mass $\geq 7$; Ota and Kohda 2006b), i.e., males/(males+females). The local OSR was used for interpopulation comparison. Mature males were found in all size classes greater than $19.7 \mathrm{~mm}$ SL. This suggests the presence of sneakers in Mtondwe as well as in Wonzye, although their spawning behaviors were not directly observed.

Interpopulation comparisons

To examine the factors that affect the expression of piracy tactics and the reproductive strategies of territorial male $T$. vittatus, we compared the data from this study and previous studies conducted at Wonzye from January to February 2003 (see Ota and Kohda 2006b) and from September to November 2004-2007 (see Ota and Kohda 2011). Local OSR, mating success, nest density, nest spatial distribution (nearest-neighbor distance), and nest size were compared as potential factors in the occurrence of piracy tactics. The local OSR and mating success at Wonzye were calculated from 2003 data ( $n=7$ nests). These parameters were compared between the populations using an ANOVA. The other parameters measured for the Wonzye population were recorded throughout all study periods from 2003 to 2007 ( $n=60$ nests). Nest density was calculated as the number of nests per study site area per year ( $n_{\text {Mtondwe }}=1$ year, $n_{\text {Wonzye }}=5$ years $)$ and thus could not be statistically examined. Of the 60 nests observed at Wonzye, 78\% (47 nests) were intruded by pirates (Ota and Kohda $\underline{2006 b}, \underline{2011}$ ). Because NND, but not nest size, influenced the intrusion strategy of pirates at Wonzye (Ota and Kohda 2011), nest size and NND were analyzed using different models. Nest size was compared between the populations using a linear mixed 
model with study years as a random factor. NND was compared among three groups [i.e., nests at Mtondwe $(n=12)$, pirated nests at Wonzye $(n=47)$, and non-pirated nests at Wonzye (n=13)] using a linear mixed model with study years and populations as random factors.

The SL of territorial males and females, and their testes investment were also compared between the populations. The SL of territorial males at Wonzye was recorded throughout all study periods from 2003 to 2007 ( $n=60)$, and that of females at Wonzye was recorded throughout all study periods from 2002 ( $n=12)$. Male SL was compared using linear mixed model with study year as a random factor. Female SL was compared using an ANOVA. The testes mass of territorial males in Wonzye was examined in 2003 (Ota and Kohda 2006a, $n=6$ ) and 2006 (Ota et al. 2010a, $n=14$ ), and in 2004 and 2005 (Ota, unpublished data; $n=16$ ). Testes investment was compared among the three nest classes using testes allometry analysis (Tomkins and Simmons 2002), in which soma mass (body mass- testes mass, covariate), study year, and population (random factors) were included.

All parameters were tested for normality before analysis. All analyses were performed using PASW 18.0. Data are presented as mean \pm SD.

\section{RESULTS}

Field study at Mtondwe

Territorial males were found at 12 nests $(48.9 \pm 3.7 \mathrm{~mm})$. Each male spent most of its time at its own nest $(56.1 \pm 4.9 \mathrm{~min} / \mathrm{h})$, but males were sometimes found at outside the nests within 1 or $2 \mathrm{~m}$ and were never observed in the other nests. Territorial males frequently attacked small conspecific individuals in and around the nest $(0.53 \pm 0.30$ attacks/min). Among all 12 nests, no males were observed visiting more than one nest or dominating territorial males. Consequently, submissive displays by territorial males were never observed in the study period. 
Larger territorial males occupied larger nests (linear regression, $r=0.70$, $F_{1,10}=9.61, P=0.01, n=12$ nests, Fig. $\left.1 \mathrm{a}\right)$, but there was no relation between SL and NND ( $r=0.002, F_{1,10}=0.001$, n.s., $n=12$ nests; Fig. $\left.1 \mathrm{~b}\right)$. At the 11 nests located outside the study site, the number of brood-caring females was positively correlated with nest size (linear regression, $r=0.82, F_{1,9}=19.0, P=0.001$ ). This implies that mating success increases with nest size in Mtondwe, as in Wonzye.

Of the 12 nests from which territorial males were removed, four were occupied by new males within 3 days after the removal. The occupied nests contained more shells than the unoccupied nests, but NND did not differ between occupied and unoccupied nests (Table 1). The males that newly occupied the vacant nests were always smaller than the original territorial males (range of size difference=1.3-6.6 $\mathrm{mm} \mathrm{SL}, n=4$ ).

Interpopulation comparison

Nest density appeared to be consistently much lower at Mtondwe $\left(0.006 / \mathrm{m}^{2}\right)$ than at Wonzye $\left(0.028-0.038 / \mathrm{m}^{2}\right)$. Consequently, the nests were much more sparsely distributed at Mtondwe (NND, 8.9 $\pm 6.9 \mathrm{~m}, n=12$ nests) than at Wonzye $(4.4 \pm 2.1 \mathrm{~m}$, $n=60$; ANOVA, $\left.F_{1,70}=17.9, P<0.001\right)$. Although there was no difference in NND between the nests at Mtondwe and non-pirated nests at Wonzye, the NND at Mtondwe was significantly greater than that of pirated nests at Wonzye (linear mixed model, $F=11.02$, num $d f=2$, den $d f=69, P<0.001, n=72$, Fig. 2). Nest size did not differ between Mtondwe (57.8 \pm 9.3 shells, $n=12$ nests) and Wonzye (73.5 \pm 32.5 shells, $n=60$ nests; linear mixed model, $F=0.41$, num $d f=1$, den $d f=4, P=0.56$ ), but the variance was considerably larger at Mtondwe. There was likewise no difference in mating success between Wonzye (mean $\pm \mathrm{SD}=1.71 \pm 1.60, n=7)$ and Mtondwe $(1.92 \pm 1.08, n=12)$ (ANOVA, $F_{1,17}=0.11, P=0.75$ ). Given a positive relationship between nest size and mating success (Ota and Kohda 2006b, this study), it could be surmised that mating success would be highly variable at Mtondwe. However, this was not the case. The number of mature males and brood-caring females per nest did not differ between the populations, and there were more males than females in the nests of both populations 
(ANOVA, sex $\times$ population: $F_{1,34}=2.56, P=0.12$; population: $F_{1,35}=3.80, P=0.06$; sex: $F_{1,35}=55.68, P<0.001$; Fig. 3). This indicates that mating success and OSR did not differ between the populations, and furthermore, local OSR was extremely male-biased in both populations. Indeed, local OSR did not differ between Mtondwe (0.90 $\pm 0.09, n=12$ nests) and Wonzye $(0.92 \pm 0.07, n=7$ nests, Mann-Whitney $U$ test, $U=36.5, P=0.65)$.

Territorial males were larger than females in both populations (Mtondwe: ANOVA, $F_{1,32}=270.0, P<0.001$; Wonzye: linear mixed model, $F=154.93$, num $d f=1$, den $d f=18, P<0.001$; Fig. 4). Male SL differed between the populations (linear mixed model, $F=9.09$, num $d f=1$, den $d f=70, P<0.01$, Fig. 4) while female size did not (ANOVA, $F_{1,32}=1.29, P=0.26$, Fig. 4). Testes investment also differed among the nests. The slopes of testes allometry did not differ among the nests (linear mixed model, soma mass $\times$ nests: $F=1.76$, num $d f=2$, den $d f=42, P=0.18$ ), whereas the intercepts (i.e., testes investment) did (nests: $F=3.62$, num $d f=2$, den $d f=44, P=0.035$ ). A difference in intercept was found between males in nests at Mtondwe and those in pirated nests at Wonzye ( $P=0.029$ ), although the difference was no longer significant when the significance level was corrected by the Bonferroni test (Fig. 5).

\section{DISCUSSION}

Contrary to Wonzye, there was no evidence that piracy occurred at Mtondwe. This is counterintuitive, given that nest piracy is a highly successful tactic (van den Berghe 1988; Calsbeek et al. 2002; Bessert et al. 2007). The benefits of piracy might be offset by its inherent costs at Mtondwe, which may result in the lack of piracy. Such costs include those associated with travelling between nests in T. vittatus (Ota and $\underline{\text { Kohda 2006b }}, \underline{2011}$ ). This cost will be strongly influenced by nest density. As nest density was much lower at Mtondwe than that at Wonzye, pirates at Mtondwe, if present, would have to spend more time travelling among nests and decrease the number of nests on which they intrude per unit time. Piscivorous fishes (e.g., Lepidiolamprologus spp. and Lamprologus lemairii) are highly populous throughout the southern regions of Lake Tanganyika (Nakaya et al. 1992), suggesting that predator abundance is similarly high 
in both Wonzye and Mtondwe. Hence, travelling among nests will expose the travelers to predation in both populations. Particularly, the travelers at Mtondwe, compared with those at Wonzye, will have increased exposure to predators during the increased time in travel between nests required there. Although the fitness of the alternative tactics has not been addressed here, higher fitness gains are expected at Mtondwe when males remain territorial than when they change to the piracy tactic as they grow. The nest density at Mtondwe would be lower than that at which the piracy tactic is adaptive. In support of this, the NND at Mtondwe was similar to that of the non-pirated nests at Wonzye and was much longer than that of the pirated nests at Wonzye.

OSR and population density might also explain the appearance of the piracy tactic because these influence individual fitness and thus the decision-making process that determines which tactic to employ (Kokko and Rankin 2006). In the European bitterling Rhodeus sericeus, for example, as OSR skews toward males (Mills and

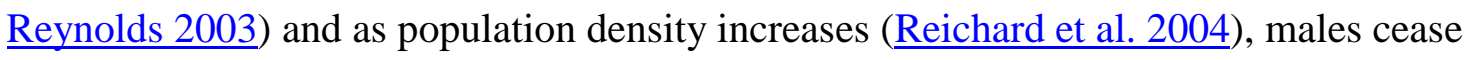
territorial defense due to increased defense costs. In the European earwig Forficula auricularia, on the other hand, the proportion of territorial males increases with population density due to increased mate encounter rate (Tomkins and Brown 2004). We found no difference in OSR between the two T. vittatus populations, but population density possibly differs between them. T. vittatus is intensively aggregated around nests, particularly at larger nests (Ota and Kohda 2006b; Ota 2007), suggesting that population density reflects nest density and size. Our findings of lower nest density at Mtondwe than at Wonzye and no difference in nest size between the populations suggest that the population density is lower at Mtondwe. However, brood-caring females were similar in numbers per nest of both populations, suggesting that the decreased population density did not directly cause a decrease in mate availability of pirates. Pirates would rather experience lower mate availability at Mtondwe because the decreased nest limits the number of nests that pirates can visit per unit time (see above). Thus, the lack of piracy will not be due primarily to a function of population density.

Territorial males exhibited different reproductive strategies between Mtondwe and Wonzye. As predicted, they seem to experience a relaxation of the selection induced 
by piracy at Mtondwe. First, we showed that at Mtondwe, larger territorial males occupied larger nests in which they may enjoy higher mating success. The male removal experiments showed that larger nests were preferentially occupied. These results indicate that territorial males compete for larger nests at Mtondwe, as found in substrate-brooding fishes (e.g., Downhower and Brown 1980; Lindström 1988; Lugli et al. 1992). This is contrast to their nest choice strategies at Wonzye where they sacrifice the fitness benefits that larger nests offer, and instead prefer to and compete for isolated nests on which pirates seldom visit so that they try to avoid pirates (Ota and Kohda 2006b, 2011). Perhaps, territorial males could not have to sacrifice the benefits of larger nests at Mtondwe because they are freed from piracy.

Second, we showed that territorial males were larger at Wonzye than at Mtondwe, resulting in a greater degree of sexual size dimorphism at Wonzye. This pattern is typically found when sexual selection acts on males in favor of larger bodies (Fairbairn 2005). As male-male competition favors larger males in T. vittatus (Ota and Kohda 2011), the result would be explained by difference in the level of sexual selection on territorial males between the populations. According to sexual selection theory (Arnold and Wade 1984; Kvarnemo and Ahnesjö 1996, but see Klug et al. 2010; Fitze and Le Galliard 2011), if this is the case, it is expected that OSR skews more toward males and male reproductive success is more variable at Wonzye. Although OSR was comparable between the two $T$. vittatus populations, the variance in male reproductive success might be greater in Wonzye. The presence of reproductive parasitism possibly influences the variance. In sand goby, for example, sneakers reduce the variance among males, resulting in a decrease in the opportunity for sexual selection (Jones et al. 2001). On the other hand, presence of the aggressive piracy tactic may make a different situation from sneaking by sneakers. In the side-blotched lizard Uta stansburiana, for example, the presence of usurping, which is a piracy-like strategy, increases the levels of aggressions, which will induce an increase in the level of sexual selection (Corl et al. 2010b). In T. vittatus, as territorial males have to compete with pirates at Wonzye, sexual selection is expected to be stronger there than at Mtondwe. Further, the extent to which territorial males monopolize access to mates increases with decreasing piracy risk at Wonzye: their reproductive success would be considerably decreased at less isolated 
nests (Ota and Kohda 2011). At Mtondwe, such reduction does not occur, and reduction in their reproductive success would primarily come from sneaking. If sneaking contributes little to their reproductive success at Mtondwe as like at Wonzye, fitness reduction seldom occurs there. Together with piracy being highly successful, the presence of piracy should increase the variance in male reproductive success. The decreased body size of territorial males at Mtondwe might therefore be explained by the relaxation of intrasexual selection enabled by the lack of piracy. Consistent with this idea, the largest pirate males (>60 mm SL) are found in another population, Kasakalawe (7 and $9 \mathrm{~km}$ away from Wonzye and Mtondwe, respectively), where nest density was as high (0.046 nests $/ \mathrm{m}^{2}$; Ota et al. 2010b) as that at Wonzye (Fitzpatrick et al. 2007). Nevertheless, further studies, such as parentage analysis and manipulative experiments, will be useful before conclusions are drawn.

We also found that territorial males at Mtondwe invested less in their testes than did pirated males at Wonzye. Theory predicts that an increased risk of sperm competition favor increased testes investment (Parker 1990). The critical effect of the presence and frequency of reproductively parasitic males on the testes investment of territorial males is known in a related Lake Tanganyika cichlid Julidochromis transcriptus (Awata et al. 2008) and other taxa (e.g., Simmons et al. 1999). In T. vittatus, the levels of sperm competition that territorial males experience increase with their vulnerability to piracy risk (Ota et al. 2010a). At Mtondwe, therefore, all territorial males should be released from sperm competition with pirates. This scenario likely explains the interpopulation difference in testes investment, but it needs to be tested because the differences were marginal and a previous experimental study did not support the scenario (Ota et al. 2010a).

The results of the present comparative study conducted in natural populations showed that piracy would not be adaptive and males do not employ this tactic at low nest density. Given that the piracy tactic follows the territorial tactic in a size-dependent manner (Ota et al. 2010a), this indicates that male T. vittatus make different reproductive life-history decisions in response to changes in nest density. Further, we suggested that male behavioral phenotypes are exposed to different intensity of 
selection pressures according to the appearance of the piracy tactic. Specifically, males employ the territorial tactic without growing larger, and probably alter their nest choice strategies and decrease testes investment at low nest density. This study was conducted in populations across a contiguous habitat, and the possibility exists that the T. vittatus populations were not genetically isolated. Thus, the present results imply that male $T$. vittatus can plastically optimize their reproductive life-history strategies in response to environmental cues. Such flexible decision-making processes are found in other systems (Gamble et al. 2003; Lukasik et al. 2006; Larison 2007) and will be one of the mechanisms affecting the frequency and appearance of ARTs.

Acknowledgments We thank the staff of the Lake Tanganyika Research Unit at the Fisheries Research Institute of Zambia for their support during field work. We are very grateful to Kaya Matsuoka and Anny Mogollon for English correction and anonymous reviewers for their helpful comments on an earlier version of this manuscript. This work was supported partly by Overseas Scientific Research grant (Ministry of Education, Culture, Sports, Science and Technology; MEXT) to M.K. and Global COE project A06 (MEXT). The present study was conducted with permission from the Zambian Ministry of Agriculture, Food and Fisheries for fish research in Lake Tanganyika. 


\section{REFERENCES}

Arnold SJ, Wade MJ (1984) On the measurement of natural and sexual selection: theory. Evolution 38:709-719.

Awata S, Takeyama T, Makino Y, Kitamura Y, Kohda M (2008) Cooperatively breeding cichlid fish adjust their testis size but not sperm traits in relation to sperm competition risk. Behav Ecol Sociobiol 62:1701-1710. doi:10.1007/s00265-008-0598-0

Balshine S, Leach B, Neat F, Reid H, Taborsky M, Werner N (2001) Correlates of group size in a cooperatively breeding cichlid fish (Neolamprologus pulcher). Behav Ecol Sociobiol 50:134-140. doi:10.1007/s002650100343

Bessert ML, Brozek J, Orti G (2007) Impact of nest substrate limitations on patterns of illegitimacy in the fathead minnow, Pimephales promelas (Cypriniformes. Cyprinidae). J Hered 98:716-722. doi:10.1093/jhered/esm092

Calsbeek R, Alonzo SH, Zamudio K, Sinervo B (2002) Sexual selection and alternative mating behaviours generate demographic stochasticity in small populations. Proc Roy Soc Lond B 269:157-164. doi:10.1098/rspb.2001.1856

Corl A, Davis AR, Kuchta SR, Sinervo B (2010a) Selective loss of polymorphic mating types is associated with rapid phenotypic evolution during morphic speciation. Proc Natl Acad Sci 107:4254-4259. doi:10.1073/pnas.0909480107

Corl A, Davis AR, Kuchta SR, Comendant T, Sinervo B (2010b) Alternative mating strategies and the evolution of sexual size dimorphism in the side-blotched lizard, Uta stansburiana: a population level comparative analysis. Evolution 64:79-96. doi:10.1111/j.1558-5646.2009.00791.x

Downhower JF, Brown L (1980) Mate preferences of female mottled sculpins, Cottus bairdi. Anim Behav 28:728-734. doi:10.1016/S0003-3472(80)80132-1

Duftner N, Sefc KM, Koblmuller S, Nevado B, Verheyen E, Phiri H, Sturmbauer C 
(2006) Distinct population structure in a phenotypically homogeneous rock-dwelling cichlid fish from Lake Tanganyika. Mol Ecol 15:2381-2395. doi:10.1111/j.1365-294X.2006.02949.x

Endler JA (1995) Multiple-trait coevolution and environmental gradients in guppies. Trend Ecol Evol 10:22-29. doi:10.1016/S0169-5347(00)88956-9

Fairbairn DJ (2005) Allometry for sexual size dimorphism: testing two hypotheses for Rensch's rule in the water strider Aquarius remigis. Am Nat (Suppl) 11:69-84. doi:0003-0147/2005/1660S4-40916

Fitze PS, Le Galliard JF (2011) Inconsistency between different measures of sexual selection. Am Nat 178:256-268. doi:10.1086/660826

Fitzpatrick JL, Desjardins JK, Milligan N, Montgomerie R, Balshine S (2007) Reproductive-tactic-specific variation in sperm swimming speeds in a shell-brooding cichlid. Biol Rep 77:280-284. doi:10.1095/biolreprod.106.059550

Gamble S, Lindholm AK, Endler JA, Brooks R (2003) Environmental variation and the maintenance of polymorphism: the effect of ambient light spectrum on mating behaviour and sexual selection in guppies. Ecol Lett 6:463-472. doi:10.1046/j.1461-0248.2003.00449.x

Gross MR (1996) Alternative reproductive strategies and tactics: diversity within sexes. Trend Ecol Evol 11:92-98. doi:10.1016/0169-5347(96)81050-0

Jones AG, Walker D, Kvarnemo C, Lindstrom K, Avise JC (2001) How cuckoldry can decrease the opportunity for sexual selection: data and theory from a genetic parentage analysis of the sand goby, Pomatoschistus minutes. Proc Natl Acad Sci 98:9151-9156. doi:10.1073/pnas.171310198

Klug H, Heuschele J, Jennions MD, Kokko H (2010) The mismeasurement of sexual selection. J Evol Biol 23:447-462. doi:10.1111/j.1420-9101.2009.01921.x 
Koblmüller S, Sefc KM, Duftner N, Warum M, Sturmbauer C (2007) Genetic population structure as indirect measure of dispersal ability in a Lake Tanganyika cichlid. Genetica 130:121-131. doi:10.1007/s10709-006-0027-0

Kokko H, Rankin DJ (2006) Lonely hearts or sex in the city? Density-dependent effects in mating systems. Phil Trans Roy Soc B 361:319-334. doi:10.1098/rstb.2005.1784

Kvarnemo S, Ahnesjö I (1996) The dynamics of operational sex ratios and competition for mates. Trend Ecol Evol 11:404.408. doi:10.1016/0169-5347(96)10056-2

Lank DB, Smith CM, Hanotte O, Burke T, Cooke F (1995) Genetic polymorphism for alternative mating behavior in lekking male ruff Philomachus pugnax. Nature 378:59-62. doi:10.1038/378059a0

Larison B (2007) Environmental heterogeneity and alternative mating tactics in the damselfly Protoneura amatoria. Behav Ecol 18:1021-1028. doi:10.1093/beheco/arm071

Lindström K (1988) Male.male competition for nest sites in the sand goby, Pomatoschistus minutus. Oikos 53:67-73

Lugli M, Bobbio L, Torricelli P, Gandolfi G (1992) Breeding ecology and male spawning success in two hill-stream populations of the freshwater goby, Padogobius martensi. Environ Biol Fish 35:37-48. doi:10.1007/BF00001156

Lukasik P, Radwan J, Tomkins JL (2006) Structural complexity of the environment affects the survival of alternative male reproductive tactics. Evolution 60:399-403. doi:10.1111/j.0014-3820.2006.tb01116.x

McNamara JM, Houston AI (1996) State-dependent life histories. Nature 380:215-221. doi:10.1038/380215a0

Mills S, Reynolds JD (2003) Operational sex ratio and alternative reproductive behaviours in the European bitterling, Rhodeus sericeus. Behav Ecol Sociobiol 
54:98-104. doi:10.1007/s00265-003-0616-1

Nakaya K, Yanagisawa Y, Kohda M, Sato T, Niimura Y, Matsumoto K (1992)

Ichthyofaunal comparison in the Zambian waters of Lake Tanganyika. Ecol Limnol Stud Lake Tanganyika Adjacent Reg 8:47-49

Nevado B, Koblmüller S, Sturmbauer C, Snoeks J, Usano-Alemany J, Verheyen E (2009) Complete mitochondrial DNA replacement in a Lake Tanganyika cichlid fish. Mol Ecol 18:4240-4255. doi:10.1111/j.1365-294X.2009.04348.x

Oliveira RF, Taborsky M, Brockmann HJ (2008) Alternative reproductive tactics: an integrative approach. Cambridge University Press, Cambridge

Ota K (2007) Reproductive tactics and sperm competition in a shell-brooding fish, Telmatochromis vittatus (Cichlidae), in Lake Tanganyika. Dissertation, Osaka City University

Ota K, Kohda M (2006a) Description of alternative male reproductive tactics in a shell-brooding cichlid, Telmatochromis vittatus, in Lake Tanganyika. J Ethol 24:9-15. doi:10.1007/s10164-005-0154-6

Ota K, Kohda M (2006b) Nest use by territorial males in a shell-brooding cichlid. The effect of reproductive parasitism. J Ethol 24:91-95.

doi:10.1007/s10164-005-0167-1

Ota K, Kohda M (2011) Social status-dependent nest choice of territorial males under reproductive parasitism in a Lake Tanganyika cichlid Telmatochromis vittatus. J Fish Biol 78:700-712. doi:10.1111/j.1095-8649.2010.02872.x

Ota K, Heg D, Hori M, Kohda M (2010a) Sperm phenotypic plasticity in a cichlid: a territorial male's counterstrategy to spawning takeover. Behav Ecol 21:12931300. doi:10.1093/beheco/arq146

Ota K, Kohda M, Sato T (2010b) Unusual allometry for sexual size dimorphism in a cichlid where males are extremely larger than females. J Biosci 35:257-265. 
doi:10.1007/s12038-010-0030-6

Parker GA (1990) Sperm competition games: sneaks and extra-pair copulations. Proc Roy Soc B 242:127-133. doi:10.1098/rspb.1990.0115

Reichard M, Smith C, Jordan WC (2004) Genetic evidence reveals density-dependent mediated success of alternative mating Behaviours in the European bitterling (Rhodeus sericeus). Mol Ecol 13:1569-1578.

doi:10.1111/j.1365-294X.2004.02151.x

Sato T, Gashagaza MM (1997) Shell-brooding cichlid fishes of Lake Tanganyika: their habitats and mating systems. In: Kawanabe H, Hori M, Nagoshi M (eds) Fish communities in Lake Tanganyika. Kyoto University Press, Kyoto, pp 219-238

Shuster SM, Wade MJ (1991) Equal mating success among male reproductive strategies in a marine isopod. Nature 350:608-610. doi:10.1038/350608a0

Simmons LW, Tomkins JL, Hunt J (1999) Sperm competition games played by dimorphic male beetles. Proc Roy Soc Lond B 266:145-150. doi:10.1098/rspb.1999.0614

Sinervo B, Lively CM (1996) The rock-paper-scissors game and the evolution of alternative male strategies. Nature 380:240-243. doi:10.1038/380240a0

Singer A, Kvarnemo C, Lindstrom K, Svensson O (2006) Genetic mating patterns studied in pools with manipulated nest site availability in two populations of Pomatoschistus minutes. J Evol Biol 19:1641-1650. doi:10.1111/j.1420-9101.2006.01114.x

Taborsky M (1994) Sneakers, satellites, and helpers: parasitic and cooperative behavior in fish reproduction. Adv Stud Behav 23:1-100. doi:10.1016/S0065-3454(08)60351-4

Taborsky M (2001) The evolution of bourgeois, parasitic, and cooperative reproductive behaviors in fishes. J Heredity 92:100-110. doi:10.1093/jhered/92.2.100 
Takahashi T (2004) Morphological and genetic distinctness of rock and shell-bed dwelling Telmatochromis (Teleostei, Cichlidae) in the south of Lake Tanganyika suggest the existence of two species. J Fish Biol 65:419-435. doi:10.1111/j.0022-1112.2004.00459.x

Takahashi T, Watanabe K, Munehara H, Rüber L, Hori M (2009) Evidence for divergent natural selection of a Lake Tanganyika cichlid inferred from repeated radiations in body size. Mol Ecol 18:3110-3119. doi:10.1111/j.1365-294X.2009.04248.x

Tomkins JL, Brown GS (2004) Population density drives the local evolution of a threshold dimorphism. Nature 431:1099-1103. doi:10.1038/nature02918

Tomkins JL, Simmons LW (2002) Measuring relative investment: a case study of testes investment in species with alternative male reproductive tactics. Anim Behav 63:1009-1016. doi:10.1006/anbe.2001.1994

Tomkins JL, Hazel WN, Penrose MA, Radwan JW, LeBas NR (2011) Habitat complexity drives experimental evolution of a conditionally expressed secondary sexual trait. Curr Biol 2:569-573. doi:10.1016/j.cub.2011.02.032

van den Berghe E (1988) Piracy as an alternative reproductive tactic for males. Nature 334:697-698. doi:10.1038/334697a0

Warner RR, Hoffman SG (1980) Population density and the economics of territorial defense in a coral reef fish. Ecology 61:772-780. doi:10.2307/1936747 
Table 1 Differences in mean \pm SD of nest traits between immediately occupied $(n=4)$ and not yet occupied $(n=8)$ nests $3 \mathrm{~d}$ after the removal of the original territorial males at Mtondwe.

Mann-Whitney $U$ test

Occupied nests $\quad$ Unoccupied nests $\quad U \quad P$

\begin{tabular}{lcccc}
\hline Number of shells & $67.5 \pm 5.2$ & $52.4 \pm 7.3$ & 0.0 & $<0.05$ \\
$\begin{array}{l}\text { Nearest-neighbor } \\
\text { distance (m) }\end{array}$ & $7.3 \pm 1.8$ & $9.7 \pm 8.4$ & 15.0 & n.s. \\
\hline
\end{tabular}




\section{Figure legends}

Fig. 1. The relationships between territorial male body size and (a) nest size and (b) nearest-neighbor distance. The line is a regression line. The relationship between body size and NND was not significant even if an outlier was excluded (linear regression, $\left.F_{1,9}=0.12, P>0.05, n=11\right)$.

Fig. 2. The differences in (a) the nearest-neighbor distance among nests at Mtondwe, and non-pirated (filled bar) and pirated nests (blank bar) of Wonzye. Asterisks indicate statistical significance. The differences found in the distance were detected even if an outlier (see Fig. 1) was excluded (linear mixed model, $F=9.38$, num $\mathrm{df}=2$, den $\mathrm{df}=68$, $P<0.001, n=71)$. Values are mean \pm SD.

Fig. 3. The number of brood-caring females (blank bar) and mature males (filled bar) found in nests at Mtondwe and Wonzye. Differences (asterisks) were found only between sexes (see text). Values are mean \pm SD.

Fig. 4. The differences in body size of females (blank bar) and territorial males (filled bar) between Mtondwe and Wonzye. Asterisks indicate statistical significances. Values are mean \pm SD.

Fig. 5. Testes allometry of territorial males in Mtondwe ( $\mathbf{\square}$, gray line), and non-pirated $(\bullet$, solid line $)$ and pirated nests $(\circ$, dashed line) of Wonzye. The lines are regression lines. 


\section{Figures}
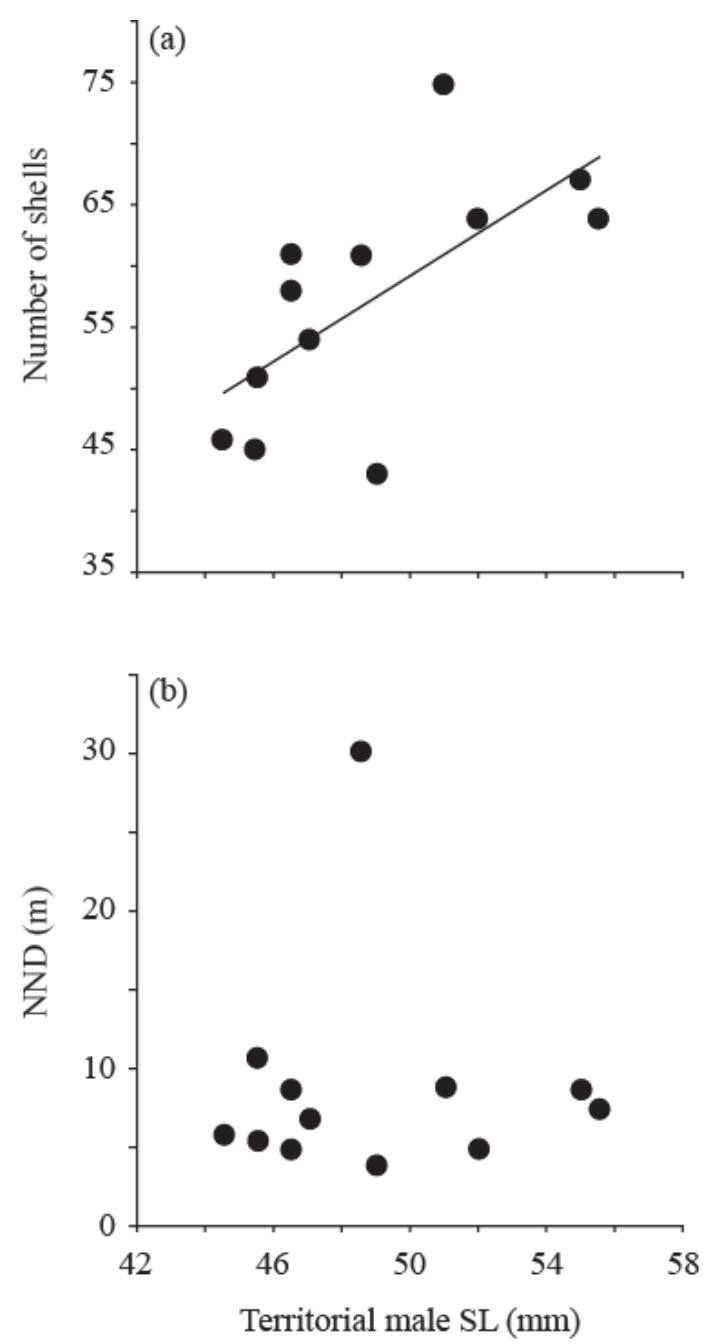

Figure 1 


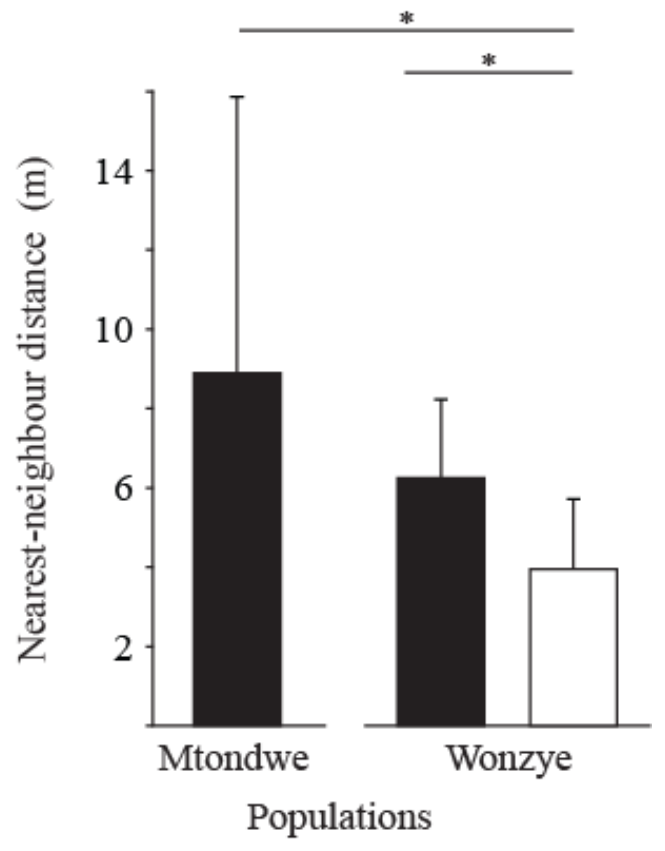

Figure 2 


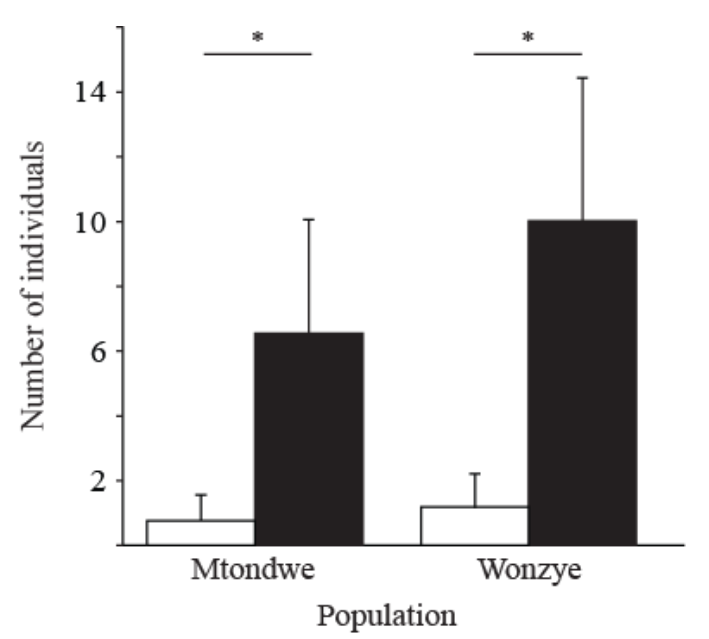

Figure 3 


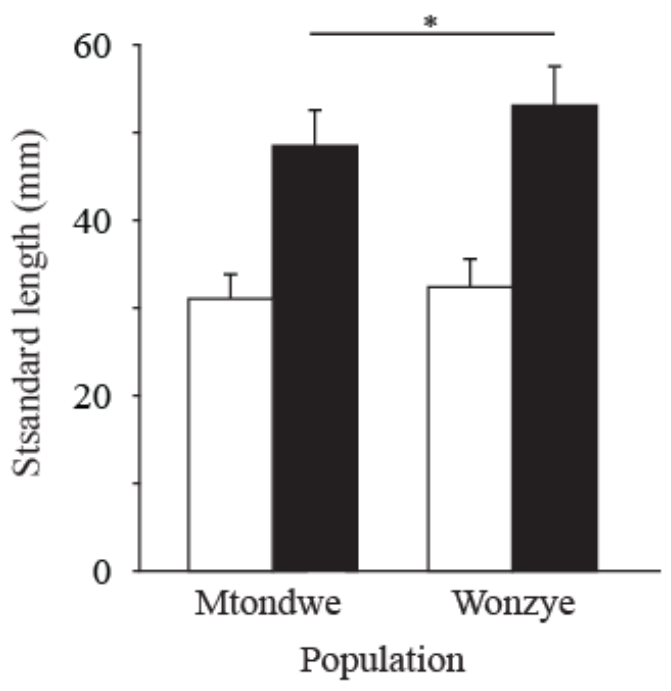

Figure 4 


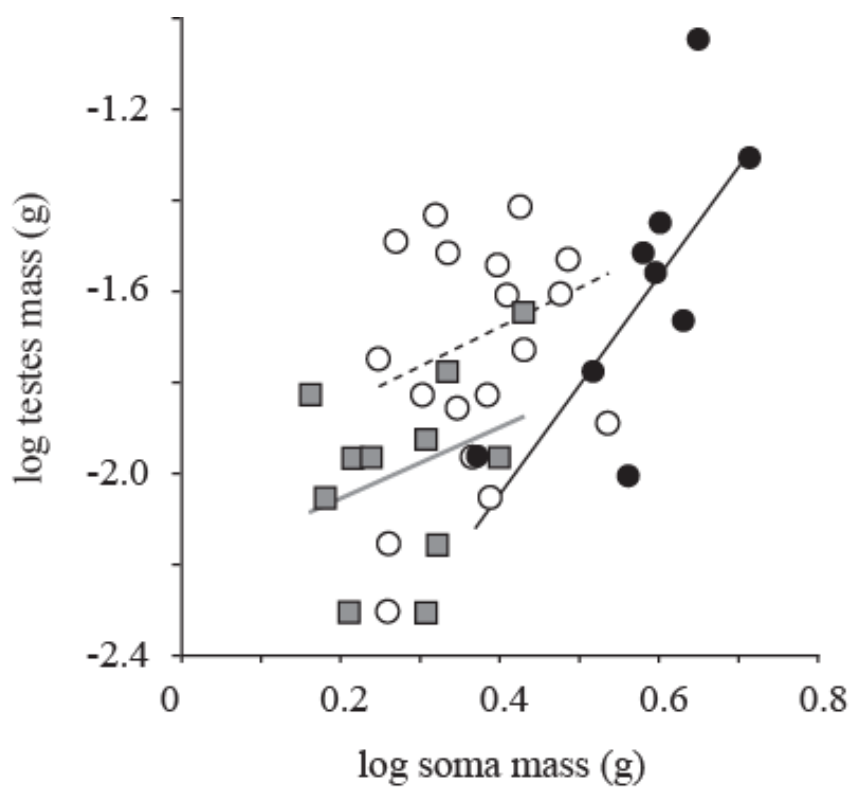

Figure 5 